\title{
CONTABILIDADE DE GESTÃO: TÉCNICAS DE CUSTEIO, GESTÃO EMPRESARIAL E ORÇAMENTAÇÃO BASEADAS NA ACTIVIDADE
}

\author{
Catarina Xavier Amaral*
}

\begin{abstract}
Neste artigo dedicamos a nossa atenção à problemática das técnicas de custeio, gestão empresarial e orçamentação baseadas na actividade num contexto em que as empresas, para alcançarem a excelência competitiva, se vêem na necessidade de melhorar continuamente o valor que oferecem aos clientes, identificando $e$ eliminando as actividades que não acrescentam valor ao produto. É esta reflexão sobre as actividades das empresas um dos contributos das técnicas baseadas na actividade para a estratégia global das empresas.

Depois de analisadas as características essenciais das técnicas baseadas na actividade, centramos a nossa atenção no desenvolvimento operacional das principais técnicas baseadas na actividade, designadamente: custeio, gestão empresarial e orçamentação, questionando-se o "real" valor das referidas técnicas.

O objectivo é demonstrar que quaisquer sistemas contabilísticos e técnicas de gestão são válidos, desde que permitam à empresa acompanhar a evolução das tecnologias, o ciclo de vida dos produtos,
\end{abstract}

\footnotetext{
* Instituto Universitário de Desenvolvimento e Promoção Social - Pólo de Viseu do Centro Regional das Beiras da Universidade Católica Portuguesa.
} 
o controlo de gestão, em suma, as mudanças das estratégias da empresa.

Palavras-chave: Técnicas Baseadas na Actividade: Activity Based Costing (ABC), Activity Based Management (ABM), Activity Based Budget (ABB), actividades, cost-drivers.

\section{CARACTERÍSTICAS ESSENCIAIS DAS TÉCNICAS BASEADAS NA ACTIVIDADE}

A primeira e por ventura a mais importante característica das Técnicas Baseadas na Actividade é a ênfase dada à análise das actividades. O que é actividade? Uma noção prática de actividade é a que a define como uma ou mais tarefas que em conjunto completam uma operação, dentro do processo organizacional.

As actividades podem ser definidas com grande detalhe ou de uma forma genérica. Por exemplo, uma empresa poderá definir como actividade a encomenda de matérias-primas, enquanto outra empresa poderá encará-la como um conjunto de várias actividades, incluindo: a verificação dos preços e qualidade; a organização dos pagamentos; e a emissão de notas de encomenda. A definição apropriada de actividade depende, em grande medida, dos objectivos pretendidos com a técnica a utilizar.

A fixação de custos baseada na actividade requer uma determinação detalhada de todas as actividades e a fixação do custo dessas actividades, através do agrupamento dos custos por actividade. Na fixação dos custos dos produtos, os agrupamentos de custos são conduzidos até aos produtos através de indutores de custo apropriados (cost-drivers). Os cost-drivers podem ser utilizados para outras funções que não a fixação do custo dos produtos, como por exemplo para análise da rendibilidade dos clientes.

A selecção e medida dos cost-drivers é outra fase crítica na implementação de um sistema de custos, contudo não é um requisito para todas as técnicas baseadas na actividade. Friedman ${ }^{1}$, no estudo que realizou a 11 empresas que implementaram técnicas baseadas na actividade, constatou que muitas delas obtiveram mais benefícios utilizando directamente a informação obtida da análise das actividades.

Uma análise de actividades, que determina se as actividades acrescentam ou não valor, é muitas vezes a base para a técnica de Gestão 
Baseada nas Actividades (Activity Based Management), a qual examina os processos organizacionais, como por exemplo: a cadeia de fornecedores ou uma mais genérica gestão de custos.

Uma segunda característica, particularmente importante nos sistemas de custo baseados na actividade (Activity Based Costing), é o conceito alargado de custo variável. Os sistemas de custeio tradicionais adoptam uma visão microeconómica do que são custos fixos e variáveis, sendo que um custo que varia directamente com o volume produzido é variável. A técnica $\mathrm{ABC}$ tem por requisito que todas as causas significativas de variabilidade sejam reconhecidas. Desta forma, o custo pode variar em função de um grande número de factores, como, por exemplo: natureza e o tamanho dos lotes, grau de complexidade do produto, número de componentes ou tipo de consumidor. São estas diferentes causas de variabilidade que dão origem a cost-drivers apropriados. Assim, para cada agrupamento de custos é necessário encontrar uma característica que permita relacionar a actividade com a utilização dos recursos consumidos por essa actividade. A compreensão de que existem múltiplas causas de variabilidade e a necessidade de encontrar indutores de custos relevantes têm como consequência um sistema de custeio onde uma proporção muito maior de custos é imputada aos objectos de custo, comparativamente com os sistemas tradicionais. De facto, o grau de correlação é uma característica fundamental na avaliação dos sistemas de custo baseados na actividade.

Nos sistemas de custeio tradicionais a decisão, quanto à magnitude de custos que devem ser imputados aos produtos, está normalmente dependente dos requisitos da contabilidade financeira. Isto deve-se ao facto de se pretender ter apenas um sistema de contabilidade que produza simultaneamente informação financeira e para a gestão. A técnica de custeio baseada na actividade requer uma maior magnitude de custos a ser incluída nas bases de custo, se os respectivos objectos forem substancialmente diferentes. Por exemplo, se um determinado produto necessitar de custos de marketing substancialmente maiores que outro, esta variabilidade deve ser incorporada no sistema de custeio, não obstante as despesas de marketing não serem normalmente consideradas como parte integrante dos custos do produto nas demonstrações financeiras. Esta abordagem significa que os custos baseados na actividade não estão conformes com os princípios do relato financeiro. Desta forma, as empresas terão de fazer ajustamentos aos seus custos internos baseados na actividade, antes de produzirem os relatos financeiros externos ou então manter dois sistemas de informação. 
Os sistemas de custeio tradicionais agrupam, normalmente, os custos tendo por base centros de custos funcionais ou departamentos, com um elevado nível de agregação que não fornece a informação detalhada necessária à tomada de muitas das decisões organizacionais, principalmente das não rotineiras.

Os sistemas baseados na actividade têm, normalmente, muitos mais agrupamentos de custos que os sistemas tradicionais, o que acrescenta um nível de flexibilidade que não existia. Esta flexibilidade da informação baseada na actividade poderá ser aumentada se for agregada de forma a que seja estabelecida uma hierarquia de custos com diferentes características. Friedman ${ }^{2}$, Cooper e Kaplan (1991) sugerem a seguinte:

\section{Figura 1}

\section{HIERARQUIA DE ACTIVIDADES}

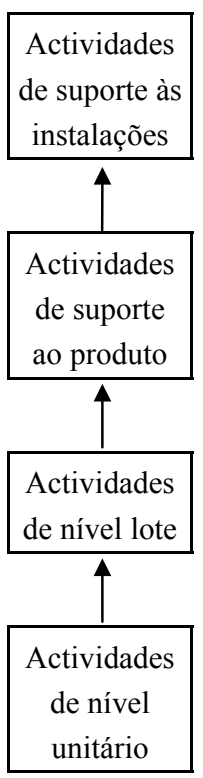

$\Rightarrow$ As actividades de suporte às instalações correspondem às actividades gerais que podem não ser específicas de nenhum produto (ex: iluminação, limpeza, segurança, etc.);

$\Rightarrow$ As actividades de suporte ao produto incluem as actividades de apoio à concepção, fabricação e comercialização de cada tipo de produto. A sua dimensão depende do número de produtos e da sua complexidade; 
$\Rightarrow$ As actividades de nível lote são aquelas que se verificam sempre que se produz um lote diferente, dependendo assim do número de ordens de fabrico. É o caso da afinação das máquinas, a movimentação dos materiais para o local de fabrico e as inspecções necessárias;

$\Rightarrow$ As actividades de nível unitário são aquelas que são requeridas sempre que se fabrica uma unidade de produto.

Com esta hierarquia, é possível extrair diferentes custos para diferentes objectivos. Se o problema for uma decisão quanto à afectação de recursos a longo prazo, deverão usar-se os custos "completos" (não obstante muitos autores considerarem que os custos de suporte às instalações nunca deverão ser imputados aos produtos, clientes, etc.). Se, por outro lado, se tratar de decisões de curto prazo, então só serão necessários os custos variáveis e, dentro da hierarquia de custos, estes corresponderão aos custos de nível unitário e de nível lote.

\section{ACTIVITY BASED COSTING (ABC) - MÉTODO DE CUSTEIO BASEADO NA ACTIVIDADE}

$\mathrm{O}$ modelo $\mathrm{ABC}$ pressupõe analisar minuciosamente o processo produtivo, desagregando-o em actividades que, independentemente do papel que possam desempenhar na gestão do próprio processo produtivo, constituem centros de localização do custo dos factores.

O núcleo central deste sistema são então as actividades, as quais podem ter origem em vários departamentos ou centros de produção. Por exemplo, o custo de controlo de qualidade é dado pela acumulação de custos relacionados com a respectiva actividade, fora e dentro da empresa, ou seja, é a soma dos custos de inspecção das matérias no departamento de compras, dos custos do controlo da produção, do custo da qualidade do serviço prestado ao cliente no departamento de vendas, etc. Para conhecer o custo de controlo da qualidade devem registar-se e acumular-se os custos daquela actividade, separando-os dos custos ocasionados por outras actividades diferentes.

\subsection{Operacionalização de um Sistema de Custeio ABC}

A operacionalização de um sistema de custeio $\mathrm{ABC}$ é orientada pelo princípio de que:

$\Leftrightarrow$ são as actividades que geram custos; 
$\leftrightarrow$ por sua vez, os produtos consomem actividades.

Este duplo princípio é complementado com a definição de um instrumento operacional de ligação dos custos das actividades aos produtos: os cost-drivers. Para além de serem medidas de consumo das actividades pelos produtos, os cost-drivers são também medidas de consumo de recursos pelas actividades, ou seja:

$\leftrightarrow$ a atribuição dos custos aos produtos deve ser feita em função das actividades consumidas por cada produto individual;

$\Leftrightarrow$ as unidades de medida dos consumos a utilizar nessa atribuição devem ser aquelas que determinam a dimensão dos custos de cada actividade: os cost-drivers.

Desta forma, a empresa deixa de ser representada como uma agregação de centros de responsabilidade, coordenados por uma estrutura, que visam, cada um de per se, minimizar os seus custos, e passa a ser vista como uma rede de processos que actuam de uma forma articulada, tendo em vista a obtenção de produtos/serviços que satisfaçam o cliente. Os custos deixam de ser assumidos como um "mal necessário" que cabe à contabilidade de gestão repartir, passando a ser vistos como o resultado de consumos de recursos, ditados pelas opções de processos de concepção, fabricação e distribuição.

As fases do processo de definição de um sistema de custeio $\mathrm{ABC}$ são as seguintes:

1. A identificação das actividades - esta fase exige uma análise pormenorizada da forma como se faz a utilização de recursos da empresa, o que pressupõe, entre outros aspectos, o levantamento da estrutura da empresa e da organização dos processos de concepção, fabrico e comercialização.

2. A escolha dos cost-dirvers das actividades - identificadas as actividades que consomem os recursos da empresa, há que seleccionar os factores que determinam o nível de recursos consumidos. Trata-se de estabelecer uma relação de causalidade entre os níveis de recursos consumidos e os outputs obtidos, sejam eles um bem, um serviço ou uma informação. O cost-driver deve ser uma unidade de medida que represente, por um lado, o objecto das actividades e, por outro, permita uma afectação razoável do custo das actividades aos outputs. Na tabela seguinte são apresentados alguns exemplos de actividades e respectivos cost-drivers: 
Tabela 1

ACTIVIDADES E COST-DRIVERS

\begin{tabular}{|l|l|l|}
\hline \multicolumn{1}{|c|}{ FUNÇÃO } & \multicolumn{1}{|c|}{ ACTIVIDADES } & \multicolumn{1}{c|}{ COST-DRIVER } \\
\hline Planeamento & Desenho de planos & Número de produtos a produzir \\
& Especificações \\
& Controlo de qualidade das \\
& Máquinas & $\begin{array}{l}\text { Número de novos produtos } \\
\text { Número de máquinas }\end{array}$ \\
\hline Produção & $\begin{array}{l}\text { Preparar as ordens de fabrico } \\
\text { Preparar as máquinas }\end{array}$ & $\begin{array}{l}\text { Número de ordens de fabrico } \\
\text { Número de máquinas } \\
\text { Horas-máquina }\end{array}$ \\
\hline Aprovisionamento & Trilização das máquinas & Número de produtos acabados \\
\hline
\end{tabular}

3. O agrupamento das actividades em função dos cost-drivers consiste em agrupar as actividades cujos consumos de recursos são determinados pelo mesmo factor explicativo, constituindo-se centros de agrupamento de actividades.

4. A imputação dos custos das actividades aos produtos é feita após a identificação das actividades da empresa, da selecção dos cost-drivers e do eventual agrupamento das actividades em função dos mesmos, podendo-se em seguida proceder à ligação das actividades aos produtos. Apurado o valor monetário dos recursos consumidos por cada actividade ou agrupamento de actividades e quantificado o cost-driver correspondente (número de unidades), calcula-se o custo unitário do cost-driver que vai permitir a atribuição dos custos da actividade aos produtos.

\section{ACTIVITY BASED MANAGEMENT (ABM) - GESTÃO EMPRESARIAL BASEADA NA ACTIVIDADE}

O ABM reconfigura a forma como as empresas gerem os seus custos. Através da compreensão das suas actividades, uma empresa poderá visionar oportunidades para uma melhoria da sua performance, que os sistemas de contabilidade de custos convencionais raramente detectariam. A gestão de custos é melhorada significativamente através da identificação daquilo que a empresa faz, o que proporciona um termo de comparação que lhe permite aferir o quanto a performance da organização poderá vir a ser melhorada. 
A visão tradicional é a de que os custos são melhor controlados pelos gestores de departamento, os quais são responsáveis pela minimização das variações existentes, para cada elemento de custo, entre os valores orçamentados e os reais. A ênfase é dada à utilização eficiente dos recursos.

O ABM assenta no pressuposto de que os custos são melhor controlados através:

$\stackrel{4}{\rightarrow}$ da gestão do conjunto de todas as tarefas realizadas dentro de uma organização;

$\Leftrightarrow$ da eliminação das actividades que não criam valor;

$\leftrightarrow$ da gestão dos factores que fazem incorrer em custos; e

$\Leftrightarrow$ da melhoria contínua das actividades que criam valor.

A ênfase é dada ao uso eficaz dos recursos.

A compreensão das actividades é um factor imprescindível ao funcionamento de um sistema ABM. Segundo Brimson ${ }^{3}$, uma actividade é uma combinação de pessoas, tecnologias, matérias-pimas, métodos e a envolvente, que produz um determinado produto ou serviço. As actividades descrevem aquilo que uma empresa faz, ou seja, a forma como o tempo é gasto e os outputs gerados.

Para ilustrar o conceito de actividade vamos agora considerar um departamento de controlo de materiais de onde fazem parte as seguintes actividades:

- manuseamento das entradas de materiais;

- manuseamento dos materiais em processo de utilização;

- manuseamento das saídas de materiais;

- armazenagem das matérias-primas;

- armazenagem dos produtos em vias de fabrico;

- armazenagem dos produtos acabados;

- gestão e administração;

- formação, etc.

Cada uma destas actividades representa um processo autónomo, realizado ao longo do tempo e que produz um output específico, como, por exemplo: movimento de materiais para a fábrica; requisições ao armazém, etc. O manuseamento de entrada de materiais inicia-se com o recebimento da requisição de materiais e termina com a sua entrega no armazém de matérias-primas ou na fábrica, para iniciar o processo produtivo. A armazenagem de matérias-primas inclui, além do mais, o controlo, o registo, o inventário e a requisição de matérias-primas.

As actividades geram custos. A forma como uma actividade é desenvolvida determina quais os factores de produção, incluindo: 
pessoas, máquinas, fornecimentos, viagens, sistemas informáticos, que são necessários. Por exemplo, a actividade de planeamento da produção necessita de uma pessoa que tome a decisão do planeamento e um sistema informático que lhe permita calcular e manipular os dados necessários a esse planeamento. $\mathrm{O} \mathrm{ABM}$ irá afectar todos esses custos à actividade de planeamento da produção e não ao departamento de planeamento, do qual essa actividade faz parte.

Imputar custos às actividades permite à empresa identificar não apenas o montante de custos em que se está a incorrer, mas também saber se os factores de produção estão a ser utilizados eficazmente. Por exemplo, a tradicional abordagem em, contabilizar indiscriminadamente $\mathrm{o}$ total de ordenados de um departamento, não permitia saber de que forma a mão-de-obra estava a ser utilizada. A determinação do tempo que cada pessoa, gasta, dentro do departamento, a realizar cada uma das actividades que desempenha é fundamental para compreender a causa do custo. Por exemplo: que tempo é que um engenheiro gasta no desenho de novos produtos ou nas alterações ao processo de fabrico?

Alterações excessivas ao processo de fabrico são normalmente um indicador da pouca interacção existente entre as funções de concepção e de produção, sendo que esta última tem necessariamente de determinar a forma como esse produto irá ser manufacturado depois de estar concebido. Similarmente, alterações significativas à concepção de novos produtos sugerem que o engenheiro responsável não estará a utilizar os componentes standardizados resultando, desta forma, num número excessivo de novos componentes a serem desenhados desnecessariamente.

Finalmente, as actividades são facilmente identificáveis por grupos tão diversos de pessoas como sejam: engenheiros, operários, técnicos financeiros e gestores de topo. Elas são facilmente compreensíveis, porque correspondem a termos e eventos familiares que ocorrem dentro da organização. Daí a importância em gerir e associar custos às actividades.

\subsection{Como Implementar um Sistema ABM}

Um sistema $\mathrm{ABM}$ é tipicamente implementado em quatro fases distintas: 
Figura 2

FASES PARA A IMPLEMENTAÇÃO DE UM SISTEMA ABM

\begin{tabular}{|c|c|}
\hline $\begin{array}{c}\text { Análise das } \\
\text { Actividades } \\
\text { Fase 1a }\end{array}$ & $\begin{array}{c}\text { Redução dos } \\
\text { custos } \\
\text { Fase } 1 \mathrm{~b}\end{array}$ \\
$\qquad \begin{array}{c}\text { Rendibilidade } \\
\text { dos produtos } \\
\text { Fase } 2\end{array}$ \\
$\qquad \begin{array}{c}\text { Sistema de } \\
\text { contabilidade de } \\
\text { actividades integrado } \\
\text { Fase 3 }\end{array}$ \\
\hline
\end{tabular}

A fase 1a consiste em recolher os dados iniciais de cada actividade. A fase $1 \mathrm{~b}$ identifica projectos específicos para melhorar a performance da empresa no curto prazo, através da eliminação de actividades ineficientes e supérfluas. A fase 2 constrói uma lista de actividades por produtos ou grupo de produtos. Os resultados obtidos com este custo de produto por actividade serve de suporte à tomada de decisões estratégicas e operacionais como por exemplo: abandonar/expandir a produção de um determinado produto; produzir/comprar; fixar preço, etc. A fase 3 constrói um sistema $\mathrm{ABM}$ que serve de suporte à melhoria contínua e previne a acumulação de custos indesejáveis.

\subsubsection{Fase 1a-Análise das Actividades}

A análise das actividades permite identificar as actividades significativas de uma empresa, com vista a estabelecer uma clara e concisa base para descrever as operações que constituem o negócio e para determinar o seu custo e performance. A análise das actividades procura compreender como funciona a empresa, com o objectivo de melhorar a sua performance ao nível do lucro, qualidade e tempo.

A análise de actividades decompõe uma grande e complexa organização nos seus processos elementares (actividades) e nos outputs gerados por essas actividades, que desta forma se tornam compreensíveis e geríveis. Segundo Brimson ${ }^{4}$, a análise das actividades baseia-se na seguinte premissa: um sistema global é grande de mais para ser gerido, enquanto que as suas partes elementares não o são. $\mathrm{O}$ objectivo é 
compreender a forma como as actividades são realizadas. Centrando a atenção no processo, facilita-se a compreensão dos factores que influenciam o custo dessas actividades. Deste modo, factores-chave como sejam alterações no volume da actividade podem ser analisados para determinar o impacto que têm no custo e na performance.

Esta fase realiza-se em três diferentes passos:

Passo $n .^{\circ} 1$ - Definição das actividades: o objectivo é desenvolver um entendimento compreensivo dos processos/actividades essenciais de uma organização e os recursos afectos a cada uma delas.

A definição de actividades é feita através do envolvimento dos gestores departamentais numa série de entrevistas estruturadas. A informação obtida através da técnica da entrevista também poderá ser obtida por meio de questionários ou da análise directa ao funcionamento da empresa.

A análise das actividades mostra:

- como é que o pessoal gasta o seu tempo;

- quem são os fornecedores da actividade;

- quem são os consumidores da actividade;

- os recursos afectos à actividade;

- os inputs e outputs da actividade;

- as medidas de análise dos outputs.

Os custos são imputados às actividades em função da relação causal que se possa estabelecer entre um factor de produção e uma actividade. Por exemplo, os custos de mão-de-obra são imputados às actividades com base nas entrevistas feitas aos gestores de departamento, onde foram identificados os trabalhadores afectos a determinada actividade e a percentagem de tempo gasta nessa actividade.

Tabela 2

EXEMPLOS DE BASES DE CAUSALIDADE TÍPICAS

\begin{tabular}{|l|l|}
\hline Factor de Produção & \multicolumn{1}{|c|}{ Medida } \\
\hline 1. Mão-de-obra & 1. Tempo \\
\hline 2. Tecnologia & 2. Horas-máquina \\
\hline 3. Instalações & $3 . \mathrm{m}^{2}$ \\
\hline
\end{tabular}

O custo de actividade é calculado através da imputação dos factores de produção a cada actividade, baseado na utilização que essa actividade faz do factor de produção e é expresso em termos de uma medida de actividade que melhor representa a variação de custo para determinado 
processo (cost-driver). A selecção de uma medida de actividade apropriada é factor crítico para o sucesso de um sistema de contabilidade de actividades. Deverá existir uma correlação directa entre a medida de actividade e os factores de produção afectos a essa actividade. Finalmente, os custos da actividade são imputados aos objectos de custo: produtos, clientes, canais de distribuição, com base na utilização que eles fazem dessa actividade.

Passo $n^{\circ} 2$ - Classificação de actividades: nas equipas de trabalho constituídas, os gestores são questionados a:

1. classificar as actividades como primárias ou secundárias;

2. classificar as actividades que criam e as que não criam valor;

3. identificar a causa do custo (cost-driver);

4. examinar os processos de negócio que transcendem os departamentos ou funções, por exemplo, a segurança.

Esta análise constitui a base para identificar áreas com potencial de melhoria.

Passo $n .^{\circ} 3$ - Identificar oportunidades de melhoria: o último passo da análise das actividades consiste em identificar uma lista inicial de oportunidades para melhorar a performance. Nesta altura, a organização já obteve uma visão clara das oportunidades de redução de custos. Essas oportunidades são escalonadas em função do balanço que é feito, entre a magnitude do ganho e o custo e esforço da mudança.

Este exercício intensivo de análise das actividades evidencia um número imediato de benefícios:

1. um elevado nível de visibilidade do potencial para melhorar custos, nomeadamente através da identificação de níveis de desperdício e de actividades que não criam valor;

2. a quantificação das melhorias através do custo das actividades;

3. um processo onde os gestores sugerem e acordam oportunidades de desenvolvimento;

4. uma grande compreensão dos custos actuais através da análise dos cost-drivers.

\subsubsection{Fase $1 b$ - Redução dos Custos}

A fase seguinte à da análise das actividades e consiste em realizar as mudanças necessárias para atingir uma melhor performance imediata, através da eliminação de actividades que representem desperdícios e que assumam recursos necessários a outras actividades. 
Para que se possa obter uma melhoria no curto prazo é necessário realizar as seguintes acções:

1. eliminar desperdícios (ou actividades que não acrescentam valor);

2. simplificar e melhorar os métodos das actividades que criam valor;

3. redesenhar o processo de negócio;

4. alterar as políticas e os procedimentos da empresa.

Uma característica comum à obtenção da excelência empresarial é a melhoria contínua. Contudo, há uma grande diferença entre redução de custos e melhoria contínua. O objectivo da redução de custos é eliminar custos, ao passo que o objectivo da performance empresarial não é apenas eliminar recursos não produtivos, mas também afectar recursos adicionais a actividades cuja performance deverá ser aumentada, com vista a melhorar a eficácia global da organização. Um exemplo para ilustrar estas diferenças é a actividade de formação profissional. Esta actividade é normalmente considerada como um custo discricionário e é frequentemente abandonada em períodos de recessão.

Contudo, tal decisão poderá ter efeitos não desejáveis no longo prazo, como se pretende ilustrar na figura seguinte:

\section{Figura 3 \\ EFEITOS DA REDUÇÃO DA ACTIVIDADE DE FORMAÇÃO PROFISSIONAL}

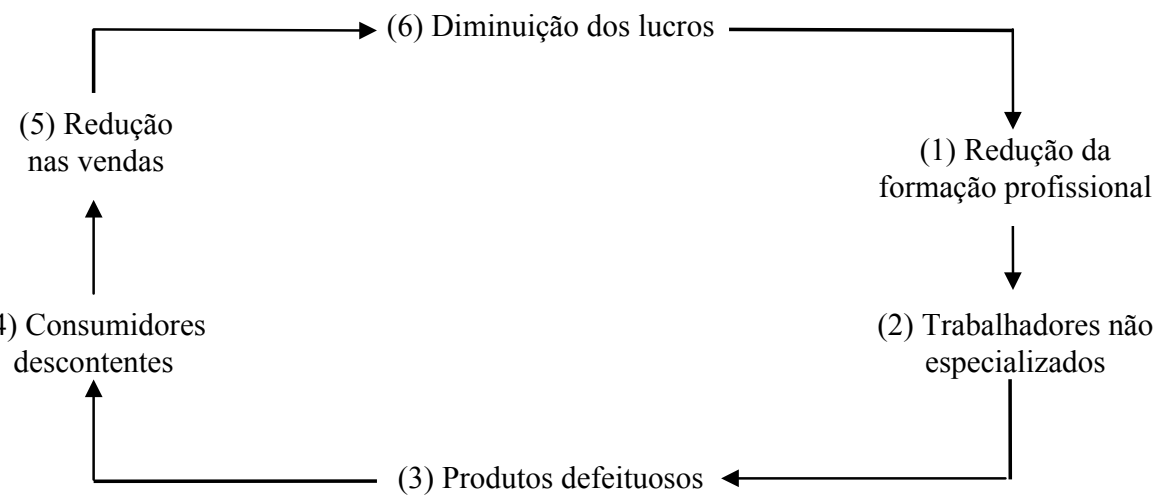

A melhoria contínua requer uma cultura em que não basta apenas detectar os problemas, é preciso encontrar as causas desses problemas e eliminá-las. O processo para reduzir custos de actividade é o seguinte: 
Figura 4

PROCESSO PARA REDUZIR CUSTOS DE ACTVIDADE

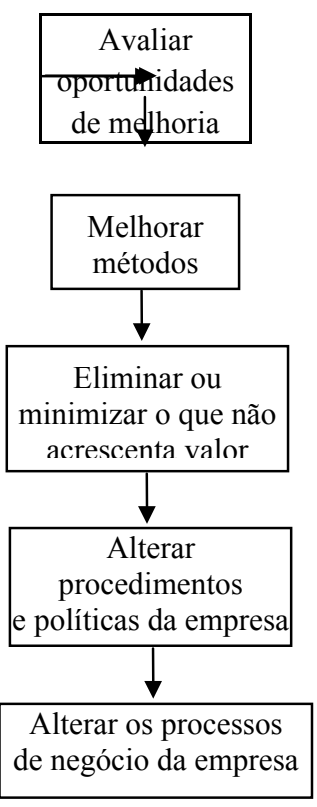

Confirmar acções
de redução de
custos
Planear e implementar projectos de redução de custos de curto prazo

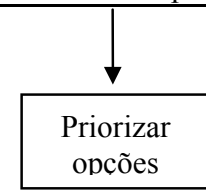

A avaliação das oportunidades de melhoria requer a preparação de um plano de acção detalhado, com vista à eliminação de actividades que não criam valor e à melhoria de curto prazo nas actividades que criam valor. A fiabilidade das oportunidades inicialmente detectadas é aqui investigada com detalhe e confirmada; é desenvolvida uma análise custo-beneficio das propostas; é feita uma selecção dos projectos e sua respectiva operacionalização.

Estes projectos de redução de custos no curto prazo podem ser feitos de várias formas:

$\leftrightarrow$ eliminar as actividades que não criam valor, i.e., fazer desaparecer actividades desnecessárias ou duplicadas;

$\leftrightarrow$ alterar os procedimentos e as políticas organizacionais que são normalmente uma causa de custos. As actividades são controladas pelos procedimentos e políticas da empresa, as quais definem os objectivos, as estratégias e os regulamentos que gerem a realização das actividades. Por exemplo: a actividade de progamar as ordens de produção poderá consistir em agrupar várias ordens de fabrico no mesmo lote para determinação da sequência produtiva, por força de um regulamento 
imposto internamente. Este tipo de política é contrário ao processo de simplificação e adiciona custos que não criam valor às actividades de produção e, como tal, deverá ser alterado.

$\stackrel{\leftrightarrow}{\rightarrow}$ alterações na organização: estruturas organizacionais inapropriadas geram custos desnecessários às empresas. A melhoria contínua conduz normalmente a mudanças organizacionais, como sejam a alteração dos métodos de controlo e da cadeia de gestão, quando estes se revelam claramente ineficientes. Uma alteração comum é a criação de uma estrutura organizacional por linhas de processo, abandonando outras estruturas do tipo por função, por produto ou por área geográfica. Outra alternativa seria a criação de uma matriz de responsabilidade funcional por processo.

$\leftrightarrow$ redução da carga de trabalho: um dos métodos mais eficazes na redução de custos é a eliminação ou redução da necessidade de realização de uma determinada actividade. As medidas de output das actividades são importantes quando se quer reduzir custos, uma vez que elas representam o volume de trabalho de uma actividade.

$\Leftrightarrow$ melhores métodos: as mudanças são efectuadas aos procedimentos com vista à melhoria da sua eficiência, através da eliminação de ineficiências óbvias, por exemplo: reforço da automação, simplificação dos trabalhos administrativos ou reestruturação dos processos. Uma forma de melhorar a função de marketing poderá consistir na elaboração de um catálogo que permita que os bens possam ser vendidos através do correio.

$\Leftrightarrow$ reconfiguração dos processos de negócio: envolve uma mudança fundamental em toda a estrutura de actividades interrelacionadas dentro do respectivo processo, por forma a permitir melhorias mais significativas, comparativamente com o que seria possível alcançar através da simples melhoria dos métodos utilizados nas actividades individuais. Por exemplo: os responsáveis por uma empresa poderão querer melhorar o processo de entrada das ordens de encomenda. Em vez de se limitar a melhorar as actividades individuais, será melhor, nesta óptica, reavaliar todo o processo: negociação, recepção e realização da ordem de encomenda. Esta reconfiguração dos processos implica as seguintes mudanças:

- simplificação através da eliminação de actividades desnecessárias ou duplicadas;

- alterar as acções de controlo por forma a que não sejam uma actividade individualizada, mas antes um produto acessório na nova estrutura. 


\subsubsection{Fase 2 - Rendibilidade dos Produtos}

A contabilidade de actividades constitui um alicerce para a obtenção de um mais preciso e relevante custo do produto, na medida em que permite que os custos sejam decompostos em separado, o que facilita a sua imputação aos produtos.

Os sistema de contabilidade de custos tradicionais definem o custo do produto como sendo a soma das matérias-primas, da mão-de-obra directa e dos gastos gerais de fabrico. Por exemplo, se considerarmos o custo de movimento de materiais, o sistema de custeio tradicional irá imputar este custo ao produto, em função do número de horas-homem ou horas-máquina consumidas. Contudo, nenhum destes critérios de repartição reflecte a necessidade que há da deslocação física dos materiais. A contabilidade de actividades irá estabelecer uma relação causal entre a actividade de movimento de materiais e a utilização que cada produto faz dessa actividade. Um exemplo dessa relação causal poderá ser o número de movimentos de materiais. Desta forma, o número de movimentos de materiais requerido para a elaboração de uma unidade de produto poderá ser utilizado para imputar o custo da actividade de movimento de materiais ao produto. Como consequência, produtos que necessitem de um maior número de deslocações irão receber um maior custo de movimento de materiais.

Os custos são imputados aos produtos em função de uma lista de actividades. Esta lista de actividades especifica a sequência das actividades a realizar e a quantidade de cada actividade consumida na produção de um determinado produto ou família de produtos. O processo produtivo pode ser descrito em termos das actividades relacionadas com a produção, incluindo aquelas que não se reflectem fisicamente no produto. Cada uma das operações de fabrico, necessárias ao processo de transformação das matérias-primas em produto acabado, é sinónimo de actividade.

Para além das actividades de produção são necessárias muitas mais actividades de suporte à fabricação do produto. O produto terá de ser desenhado; mão-de-obra, máquinas, instalações e materiais terão de ser adquiridos; o processo de fabrico planeado e controlado; o produto comercializado e expedido; a performance da empresa relatada interna e externamente. Cada uma destas actividades consome recursos, as quais deverão ser relacionados com o produto. A lista de actividades deverá, assim, incluir todas as actividades realizadas durante o ciclo de vida do produto. 
A contabilidade de actividades, contrariamente à convencional ênfase dada ao produto, enfatiza as actividades produtivas e não o produto. A nova filosofia é a seguinte: actividades realizadas de forma eficiente conduzem a produtos competitivos. A contabilidade de actividades assume o pressuposto de que os recursos são consumidos na realização das actividades e que os produtos consomem actividades.

Neste novo contexto, a lista de actividades assume particular importância, pois torna a gestão capaz de compreender a quantidade e o custo das actividades necessárias à produção de um determinado produto. A ênfase é dada aos processos individuais, por forma a que as melhorias possam ser dirigidas a esses factores controláveis pela empresa e operacionalizadas.

A lista de actividades é elaborada da seguinte forma:

Passo 1 - consiste em especificar todas as actividades ou processos de negócio necessários ao fabrico do produto e respectivo custo total;

Passo 2 - para cada uma das actividades relacionadas, directa ou indirectamente, com uma ordem de fabrico, determina-se a respectiva quantidade consumida na produção de uma unidade de produto. Por exemplo, as actividades relacionadas com o ciclo de vida do produto (investigação e desenvolvimento, publicidade, etc.) deverão ser convertidas numa base unitária em função do volume de vendas previsto. Isto é feito, dividindo o custo total da actividade pela previsão do número de unidades a serem vendidas.

Passo 3 - consiste em obter, do sistema de contabilidade de actividades, uma taxa padrão por actividade;

Passo 4 - consiste em determinar o custo total da actividade, multiplicando o número de outputs dessa actividade pela respectiva taxa padrão;

Passo 5 - consiste em determinar o custo das matérias-primas e de outras matérias subsidiárias e de consumo adquiridas. Este custo obtém-se adicionando ao preço de aquisição todos os custos incorridos para que as actividades possam ter acesso a essas matérias. Estamos, obviamente, a falar de todas as despesas adicionais de compra (fretes, seguros, transporte), encargos de armazenagem e inspecção.

Passo 6 - tratamento dos custos de infra-estrutura que não têm nenhuma relação causa-efeito com a obtenção do produto. Estes custos deverão ser identificados e caberá à gestão decidir se os afectará arbitrariamente aos produtos, para ter um custo total "completo" ou se, pelo contrário, os considerará como custos do período, uma vez que não 
são influenciados por qualquer tipo de decisão que diga respeita ao produto;

Passo 7 - consiste em determinar o custo do produto, somando os custos das actividades individuais relacionadas com o custo total das matérias consumidas.

$\mathrm{O}$ custo do produto, assim determinado, deverá ser utilizado com cautela para efeitos de decisões estratégicas, nomeadamente o abandono ou a expansão de uma família de produtos. Existe uma tendência natural da gestão para fazer alterações ao nível do produto-mix, quando o novo custo do produto baseado na actividade se afasta consideravelmente do custo obtido pelo sistema de custeio tradicional. Tais alterações radicais devem ser tomadas de uma forma ponderada. As acções a tomar, perante uma tal discrepância de valores, deverão fundamentar-se na análise cuidada das actividades que foram imputadas aos produtos, com vista a determinar onde é que possíveis melhorias de performance se poderão realizar, tendo sempre por base os factores críticos de sucesso. Por outras palavras, a margem de lucro de um determinado produto poderá não ser tão lucrativa como a de outros produtos oferecidos pela empresa. Contudo, antes de uma empresa decidir abandonar ou reduzir a produção de produtos menos rentáveis, deverá estudar primeiro o produto para determinar qual será a sua margem de lucro se actividades supérfluas forem eliminadas e se actividades que acrescentam valor forem melhoradas. As decisões estratégicas deverão ser tomadas com base na margem de lucro potencial e não com base na margem de lucro actual.

\subsubsection{Fase 3 - Sistema de Contabilidade de Actividades Integrado}

Uma empresa que procura a excelência empresarial não deve apenas eliminar o desperdício e manter a realização das actividades que criam valor (Fase 1b) mas deve, principalmente, implementar acções preventivas para evitar, desde logo, a ocorrência quer de desperdícios quer de ineficiências, ou seja, a empresa não pode estar continuamente a "apagar incêndios" (redução de custos), antes, pelo contrário, deverá evitar esses "incêndios" (prevenção da ocorrência de custos indesejáveis).

Para que uma empresa tenha sucesso no seu objectivo de prevenção de custos, deverá:

1. adoptar projectos estratégicos com vista a garantir melhorias a longo prazo; 
2. implementar um sistema de contabilidade de actividades integrado que forneça a informação indispensável para que a empresa continue na sua senda de melhoria contínua e prevenção de custos;

3. alterar o sistema de suporte às decisões para um sistema baseado na actividade, por forma a melhorar o processo de decisão.

Um factor primordial na busca da melhoria contínua é o estabelecimento de benchmarks, como, por exemplo, níveis de performance standards, que permitam à gestão saber até onde pode ir a sua performance, o que proporciona um incentivo à melhoria contínua.

Para além da fixação de benchmarks, a melhoria de longo prazo exige o estabelecimento de procedimentos que permitam gerir de uma forma contínua os cost-drivers da empresa, isto porque a análise dos cost-drivers permite identificar a causa dos custos incorridos pela organização.

Por exemplo, o layout da fábrica é um factor determinante do custo de movimento de materiais e de produtos em vias de fabrico. Uma empresa, organizada por grupos de máquinas semelhantes, tem necessariamente significativos movimentos de materiais (resultando em elevados custos de stocks de produtos em vias de fabrico) para cada máquina, à medida que a componente está a ser fabricada. Se, pelo contrário, a fábrica se organizar por processos produtivos, i.e., agrupar no mesmo local o conjunto de máquinas que permitem a produção completa da componente, minimiza substancialmente esses custos.

O desenvolvimento contínuo de um sistema de contabilidade de actividades é determinante para a melhoria contínua. Os gestores necessitam que a informação obtida seja compatível com os objectivos da excelência empresarial e atempada, para produzir acções efectivas. A informação baseada na actividade é a que conceptualmente permite atingir estes objectivos, porque realça a forma como as actividades estão a ser desenvolvidas, quer a nível departamental, quer interdepartamental.

Os requisitos básicos de um sistema de contabilidade de actividades são os seguintes:

$\leftrightarrow$ obter os custos actuais para compará-los com os planeados, ao nível da actividade;

$\Leftrightarrow$ obter níveis actuais de realização das actividades;

$\Leftrightarrow$ identificar custos que não acrescentam valor;

$\leftrightarrow$ identificar padrões óptimos de performance das actividades, por forma a compreender o desvio existente na performance actual;

$\Leftrightarrow$ identificar medidas de performance total - custo por output, tempo e qualidade - e respectivas tendências. 
O sistema de contabilidade de actividades integrado deverá ser concebido por forma a incorporar as mudanças organizacionais e mantido actualizado, uma vez que as organizações estão constantemente em mutação, quer a nível tecnológico e de filosofia de gestão, quer da introdução de novos produtos. Só assim é que as empresas conseguem ter um sistema de gestão de custos flexível, que lhes permita introduzir todo e qualquer tipo de mudanças sem terem de reestruturar o próprio sistema.

\section{ACTIVITY BASED BUDGET (ABB) - ORÇAMENTAÇÃO BASEADA NA ACTIVIDADE}

Os princípios e as metodologias fundamentais do sistema $\mathrm{ABC} / \mathrm{ABM}$ constituem uma base poderosa para o processo de orçamentação. $\mathrm{O} A B B$ não é mais do que uma progressão lógica do $\mathrm{ABC} / \mathrm{ABM}$.

\subsection{O Processo ABB}

O processo de orçamentação baseado na actividade, num contexto de planeamento estratégico, obedecerá às seguintes etapas: 


\section{Figura 5}

PROCESSO ABB

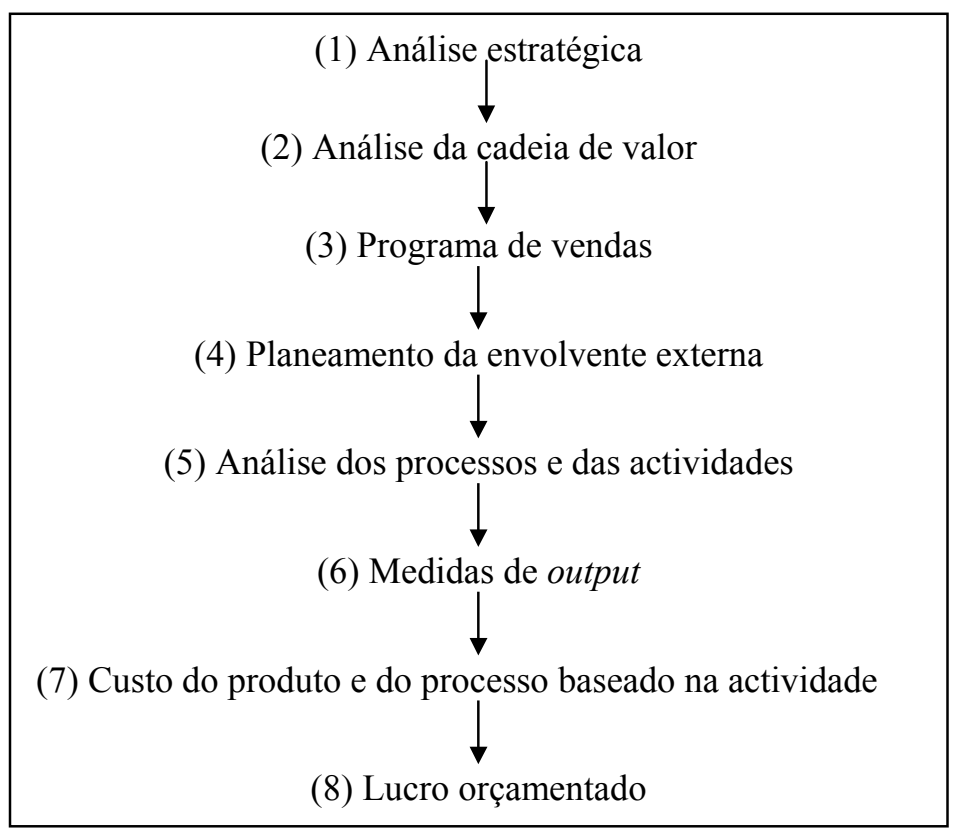

(1) Análise Estratégica - é um elemento bastante importante do processo $\mathrm{ABB}$, pois é o elo de ligação com todo o processo de planeamento estratégico da empresa e ajuda a formular toda a metodologia de trabalho, dentro da qual o $\mathrm{ABB}$ terá de ser desenvolvido.

O ABB inicia-se com a revisão dos factores críticos da empresa, tais como: insatisfação dos clientes, baixa produtividade, competitividade crescente e outros factores que constem das estratégias adoptadas pela organização, com vista à sua inclusão no orçamento. $\mathrm{O}$ ABB irá centrar-se na quantificação e na gestão destes factores críticos de sucesso.

Se a estratégia da empresa consistir em reduzir a insatisfação dos clientes, uma análise de mercado tenderá a indicar que esta insatisfação poderá ter como causa o preço, a qualidade ou os tempos de entrega do produto. Para cada um destes factores a gestão irá delinear uma determinada estratégia, de acordo com o seguinte quadro: 
Tabela 3

ESTRATÉGIA A DESENVOVER PARA CADA FACTOR CRÍTICO DE SUCESSO

\begin{tabular}{|c|c|}
\hline FACTOR & ESTRATÉGIA \\
\hline Preço $=$ & Redução do custo \\
\hline Qualidade & Introduzir um sistema de gestão da qualidade \\
\hline Entrega & $\begin{array}{l}\text { Reorganizar o processo de forma a reduzir os } \\
\text { tempos de entrega }\end{array}$ \\
\hline
\end{tabular}

Em função do factor crítico de sucesso, o $\mathrm{ABB}$ deverá integrar a respectiva estratégia no orçamento.

(2) Análise da cadeia de valor - este elemento do $\mathrm{ABC} / \mathrm{ABM}$ pode servir como uma ferramenta poderosa na elaboração de orçamentos eficazes. Um exame atento à cadeia de valor indicará, com alguma certeza, quais os processos e actividades que se adaptam ou não às estratégias propostas. Isto permite à gestão eliminar as actividades e os processos não estratégicos (os que não acrescentam valor e os que não são essenciais).

(3) Programa de vendas - consiste em determinar as quantidades de produto que os clientes provavelmente irão adquirir, tomando em consideração a estratégia da empresa e a análise da cadeia de valor. Este programa de vendas terá de ter em consideração as políticas de stock definidas pela empresa e outros constrangimentos organizacionais. $\mathrm{O}$ programa de vendas é então transcrito para acções específicas, tais como:

- número de quantidades que deverão ser produzidas a um custo específico;

- percentagem de entregas que deverá ser realizada de acordo com o planeado;

- número máximo de defeituosos que irão ser tolerados pelo sistema de gestão da qualidade.

Por exemplo, vamos supor que uma empresa, com vista a atingir a sua estratégia, decide fazer o seguinte planeamento:

$\begin{array}{ll}\text { Vendas } & 17000 \text { unidades } \\ \text { Preço de venda } & 365 \text { u.m./unidade } \\ \text { Tempo de entrega } & 72 \text { horas } \\ \text { \% normal de defeituosos } & 5 \% \\ \text { Redução de stocks } & 2000 \text { unidades } \\ \text { Lucro líquido pretendido } & 800000 \text { u.m. }\end{array}$


A previsão de vendas e redução de stocks planeada obriga à produção de 15000 (17000 - 2000) unidades de produto, de acordo com os padrões de qualidade da empresa. Isto implica que, com uma taxa de defeituosos normal de 5\%, terão que produzir-se 15790 (15 000/95\%) unidades de produto. Deste modo, a produção terá de planear os seus recursos por forma a cumprir com o delineado. Similarmente, os recursos de distribuição deverão ser planeados por forma a garantirem o requisito de entrega em 72 horas.

(4) Planeamento da envolvente externa - este planeamento consiste em obter orientações macro e micro-económicas, como, por exemplo: taxa de inflação prevista, taxa de juro prevista, taxas de crescimento, política de dividendos e outros factores exógenos que deverão ter-se em conta no processo de planeamento.

(5) Análise dos processos e das actividades - consiste em analisar e definir os processos e respectivas actividades necessárias à obtenção do output definido. Os processos poderão ser redefinidos ou reestruturados através da eliminação das actividades que não criam valor.

(6) Medidas de output - estas necessitam de ser determinadas para todas as actividades com vista a calcular, para efeitos de custo dos produtos, as taxas de actividade. Por exemplo, a actividade de processamento de encomendas terá como medida de output o número de notas de encomendas recepcionadas, que depois poderá ser utilizada para imputar o custo da actividade aos produtos que receberam essas ordens.

(7) Custo do produto e do processo baseado na actividade - todo o processo de orçamentação baseado na actividade termina com o cálculo do custo dos processos, actividades e produtos orçamentados. A técnica $\mathrm{ABB}$ é em tudo semelhante ao método $\mathrm{ABC}$. Contudo, não se determinam os custos reais nas condições actuais, mas sim os orçamentados com base nas medidas - padrão das actividades e nas estratégias definidas pela organização. Um orçamento assim construído terá grande utilidade para a gestão, uma vez que decisões importantes como sejam: reestruturação de actividades de elevado custo, eliminação de produtos não rentáveis, alterações de canais de distribuição e de marketing - poderão ser tomadas com base na informação fornecida.

(8) Lucro orçamentado - o processo termina com a análise do resultado do orçamento. Quanto o resultado obtido não se aproximar do inicialmente previsto, a gestão deverá centrar toda a sua atenção na eliminação das ineficiências e desperdícios revelados no orçamento. Uma análise cuidada poderá ainda revelar outras medidas de acção que possam 
aumentar a rendibilidade da empresa, nomeadamente: melhor utilização da capacidade instalada, uma mais efectiva utilização dos recursos, etc.

\subsection{Diferenças entre o ABB e os Orçamentos Convencionais}

Apesar do $\mathrm{ABB}$ e dos orçamentos convencionais terem muito em comum, existem diferenças importantes que poderão ser realçadas, tais como:

1. O ABB assenta na cadeia de valor apropriada, necessária para que a organização atinja os seus objectivos estratégicos, a qual assume pouca relevância nos orçamentos convencionais.

2. O programa de vendas é determinado numa perspectiva do consumidor e não numa perspectiva imposta pela organização. A ênfase é dada àquilo que os consumidores pretendem e não ao que a organização quer.

3. O ABB difere fundamentalmente dos orçamentos convencionais, porque faz a análise dos custos por actividades e não por centros de responsabilidade. $\mathrm{O}$ ABB questiona a existência de cada actividade, classificando-a como criando ou não valor.

4. Os orçamentos convencionais classificam os custos em matérias-primas, mão-de-obra directa, gastos gerais de fabrico fixos e variáveis no que respeita aos custos de produção, sendo que todos os outros custos não industriais são classificados de uma forma global em custos de distribuição ou administrativos. O ABB "estica" a classificação dos custos horizontalmente dentro da empresa, desde a compra das matérias até ao dia em que o cheque do cliente entra em caixa.

5. O sistema $\mathrm{ABB}$ requer um nível de compreensão detalhado de todas as actividades necessárias, não apenas da produção do produto, mas também da forma como esse produto chega até ao consumidor final, através dos canais de distribuição e marketing. Os orçamentos convencionais normalmente não requerem um grau de análise tão pormenorizado.

6. O ABB permite afectar a informação de custo não apenas aos produtos mas a outros objectos de custo, como sejam, o cliente e os canais de distribuição e marketing.

7. Uma das grandes vantagens do $\mathrm{ABC}$ é a sua preocupação com a informação não financeira. Do ponto de vista orçamental, este atributo conduz a uma perspectiva diferente na elaboração dos orçamentos, pois nestes passa a centrar-se a atenção naquelas actividades imprescindíveis 
ao eficaz funcionamento da organização, incorporando naqueles normas e objectivos não financeiros, como sejam as medidas de performance das actividades.

8. Quando o sistema $\mathrm{ABB}$ interage com o sistema de gestão da qualidade torna-se possível incorporar nos orçamentos a determinação do valor dos desperdícios, no ponto onde eles ocorrem.

\section{CRÍTICAS ÀS TÉCNICAS BASEADAS NA ACTIVIDADE}

Todas as teorias, novas ou não, são sempre alvo de críticas e de aceitação. Como é óbvio, as técnicas baseadas na actividade também não escapam a esta tendência, principalmente o método $\mathrm{ABC}$.

$\mathrm{O} A B C$ continua a ser um sistema de custeio, uma forma de imputar custos e, desde que haja custos indirectos a imputar, nunca poderá haver um "verdadeiro" custo de produto. Os críticos questionam se a noção de "causa-efeito" do $\mathrm{ABC}$ não será mais do que um sistema de imputação mais sofisticado e, sendo assim, o ABC, do ponto de vista conceptual, não seria um avanço aos sistemas tradicionais. Este argumento é particularmente relevante quando se trata de custos conjuntos.

Decisões que se baseiam em custos dos produtos, obtidos com base em imputações, serão sempre suspeitas, pois existirão sempre outros métodos de imputação que proporcionarão diferentes custos dos produtos, com raciocínios igualmente válidos. Os defensores do $\mathrm{ABC}$ argumentam que, em muitas circunstâncias, existe uma elevada proporção de custos indirectos que podem ser afectados directamente aos objectos de custo, usando o conceito de actividade/cost-driver. E mais: é o próprio conceito de actividade que permite que uma maior proporção de custos seja tratada como directa ou correlacionável. Em nosso entender, os custos dos produtos baseados na actividade não são perfeitos, mas poderão representar uma melhor estimativa da utilização dos recursos actuais que os sistemas tradicionais e, como tal, poderão ser mais úteis.

Segundo Bromwich e Bhimani ${ }^{5}$, as técnica baseadas na actividade têm uma grande orientação interna (o $\mathrm{ABC}$ é fundamentalmente um sistema de custos interno), correndo o risco de se tornarem introspectivas. De acordo com os mesmos autores, as empresas necessitam de ter uma visão do exterior, uma estratégia baseada no mercado, o que poderá ser conseguido através de uma Contabilidade de Gestão Estratégica. Como é pouco provável que as empresas introduzam, em simultâneo, mais do que uma mudança substancial nos seus sistemas contabilísticos, as técnicas 
baseadas na actividade podem ser consideradas como um entretenimento que consome recursos de gestão que poderiam ser melhor utilizados. Bromwich e Bhimani ${ }^{6}$ evidenciam este ponto de vista ao afirmarem, por exemplo: que o $\mathrm{ABC}$ reforça a fixação dos preços com base nos custos, quando as empresas deveriam procurar obter os seus preços de venda com base nas informações do mercado; e que o $\mathrm{ABC}$ reforça uma estratégia de produção em grande quantidade, quando uma análise estratégica poderá indicar que será preferível produzir de forma diferenciada.

Segundo Friedman ${ }^{7}$, Cobb, Innes e Mitchell (1992) referem, como crítica à implementação das técnicas baseadas na actividade, a enorme quantidade de tempo e recursos organizacionais envolvidos, o que poderá resultar no não cumprimento do critério custo-benefício. Ou os custos baseados na actividade não diferem substancialmente dos obtidos pelos sistemas tradicionais e, nesta situação, o benefício da análise é mínimo; ou então os custos envolvidos para obter "bons" custos baseados na actividade são de tal forma elevados que ultrapassam os benefícios de ter uma informação de melhor qualidade.

Os mesmos autores, referidos por Friedman, acrescentam uma outra crítica à introdução das técnicas baseadas na actividade, a qual diz respeito às dificuldades encontradas pelas empresas, por eles analisadas, em identificar as actividades e os cost-drivers, o que indicia que a implementação das técnicas baseadas na actividade pode ser mais difícil do que seria de esperar, o que se poderá tornar num obstáculo para a difusão e adopção destas técnicas nas empresas.

Ainda na mesma obra, Friedman refere que Innes e Mitchell (1990) e Bromwich e Bhimani (1994) afirmam que ainda não foi possível demonstrar, formalmente, que a utilização das técnicas baseadas na actividade melhoraram a rendibilidade de médio e longo prazo das empresas que as implementaram. Existem muitos estudos de casos e evidências empíricas que mostram que as técnicas baseadas na actividade poderão melhorar a rendibilidade das empresas através de vários caminhos: melhor fixação do preço, melhor conjunto de decisões e uma melhor gestão dos custos indirectos. Contudo, até à data, ninguém se atreveu a fazer um estudo sistemático das consequências financeiras da implementação das técnicas baseadas na actividade. É argumentado que tal estudo estará condenado ao fracasso em termos metodológicos, uma vez que o conjunto de mudanças que ocorreram em nome destas técnicas e o grande número de outras técnicas de gestão que, entretanto, foram implementadas (Just In Time, Total Quality Management, etc.), não permitem uma avaliação idónea das técnicas baseadas na actividade. 
Friedman, na análise que fez ao grupo de 11 empresas que implementaram as técnicas baseadas na actividade, constatou que a introdução das técnicas baseadas na actividade não trouxe, praticamente, nenhuma consequência inesperada. As consequências mais significativas surgiram da análise detalhada das actividades (descoberta da existência de actividades duplicadas e surpresa quanto ao custo dos recursos gastos em reuniões) e não na existência de grandes diferenças no que respeita ao custo dos produtos, ao contrário do que a análise da primeira literatura sobre ABC sugeria.

Como consequência, a informação baseada na actividade, em vez de ter consequências operacionais significativas, mostrou-se mais como um meio de quantificar os efeitos das mudanças já identificadas por outros processos.

Isto não quer dizer que os benefícios da informação gerada pelas técnicas baseadas na actividade seja irrelevante.

Muitas empresas referiram que, apesar da informação obtida pelas técnicas baseadas na actividade não ter sido surpreendente e de muitas das medidas que foram tomadas com base nesta informação já terem sido identificadas e, possivelmente, tomadas sem esta informação, o que as empresas fazem notar é que se esta informação não estivesse disponível, as decisões demorariam muito mais tempo a implementar, por falta de suporte documental.

\section{CONCLUSÃO}

Do estudo destes métodos podemos concluir que uma empresa, para alcançar a excelência competitiva, tem necessidade de melhorar continuamente o valor que oferece ao cliente, identificando e eliminando as actividades que não acrescentam valor ao produto. É esta reflexão sobre as actividades, que acrescentam ou não valor para o cliente, um dos contributos das técnicas baseadas na actividade para a estratégia global da empresa.

$\mathrm{A}$ inovação do modelo $\mathrm{ABC}$, se existe, está na visão transversal da empresa e no método de gestão utilizado, devido ao facto de a noção de actividade ser o factor mais importante de toda a análise, permitindo também que se ponha em causa o interesse das próprias actividades.

A contabilidade de gestão não deve ter por objectivo encontrar a melhor base de afectação dos custos; o seu objectivo deve ser estimar um 
modelo explicativo da existência desses custos (o custo é um efeito e não uma causa) e que possa ser utilizado pelos gestores para fins previsionais.

Neste contexto, o ABM poderá assumir particular destaque, pois ao identificar cada actividade como um processo, onde a ênfase é dada não aos sintomas (efeitos) mas sim às fontes (causas) dos custos, e se utilizar essa informação num quadro de controlo de gestão a priori, estará de certa forma a contribuir positivamente para a melhoria contínua da actividade da empresa, tornando-a mais competitiva.

Os gestores necessitam de informação sobre as actividades que lhes possibilite atingir a excelência empresarial, que consiste na integração efectiva do custo de todas as actividades realizadas pela organização, para que de uma forma contínua lhe permita melhorar a distribuição de produtos e serviços, com vista à satisfação dos seus clientes.

A contabilidade de actividades identifica aquilo que a organização faz. Com vista a melhorar a rendibilidade e a performance da organização torna-se fundamental compreender onde é que o seu precioso tempo está a ser consumido, ou seja, o que é que a organização faz e de que forma é que o está a fazer. Em última análise, uma organização só poderá melhorar no momento em que a gestão compreender o que está a ser feito e se está a ser ou não feito da melhor maneira e, também, se tais realizações contribuem ou não para atingir os objectivos organizacionais.

$\mathrm{O}$ ABB assume particular relevância enquanto modelo que permita prever as consequências das mudanças, quer nas actividades, quer nas redes de distribuição, ou prever as alterações das variáveis de marketing ou da concepção de produto.

De todo o estudo efectuado, se conclui que quaisquer sistemas contabilísticos e técnicas de gestão são válidos, desde que permitam à empresa acompanhar a evolução das tecnologias, o ciclo de vida dos produtos, o controlo de gestão, em suma, as mudanças das estratégias da empresa.

\section{NOTAS}

${ }^{1}$ FRIEDMAN, A. L. e Lyne S. R. (1995), Activity-Based Techniques: The Real Life Consequences, CIMA, Londres.

${ }^{2}$ FRIEDMAN, A. L. e Lyne S .R. (1995), Activity-Based Techniques: The Real Life Consequences, CIMA, Londres.

${ }^{3}$ BRIMSON, J. A. (1992), Management Accounting Handbook: The Basics of Activity Based Management, CIMA. 
${ }^{4}$ BRIMSON, J. A. (1992), Management Accounting Handbook: The Basics of Activity Based Manangement, CIMA.

${ }^{5}$ BROMWICH, M. e A. Bhimani (1994), Management Accounting: Pathways to Progress, CIMA, London.

${ }^{6}$ BROMWICH, M. e A. Bhimani (1989), Management Accounting: Evolution not Revolution, CIMA, London.

${ }^{7}$ FRIEDMAN, A. L. e Lyne S. R. (1995), Activity-Based Techniques: The Real Life Consequences, CIMA, Londres.

\section{REFERÊNCIAS BIBLIOGRÁFICAS}

BRIMSON, J. A. (1992), Management Accounting Handbook: The Basics of Activity Based Management, CIMA, Londres.

BROMWICH, M. e A. Bhimani (1989), Management Accounting: Evolution not Revolution, CIMA, Londres.

BROMWICH, M. e A. Bhimani (1994), Management Accounting: Pathways to Progress, CIMA, Londres.

CARREIRA, José M. J. (1996), “Activity Based Costing: de Sistema de Custeio a Instrumento de Controlo de Gestão", Revista de Contabilidade e Comércio, $\mathrm{n}^{\mathrm{o}}$ 212, Vol. LIII, Novembro.

CASTElló TAliani, Emma e Lizcano J. A. (1994), El Sistema de Gestión y de Costes Baseado en las Actividades, Instituto de Estudios Económicos, Madrid.

COOPER, R. e outros (1992), Implementing Activity-Based Cost Management: Moving from Analysis to Action, Institute of Management Accountants, New Jersey.

FRIEDMAN, A. L. e Lyne S. R. (1995), Activity-Based Techniques: The Real Life Consequences, CIMA, Londres.

GLAD, E. e H. Becker (1996), Activity-Based Costing and Management, WILEY, West Sussex.

JOHNSON, H. T. e Kaplan R. S. (1987), Relevance Lost: The Rise and Fall of Management Accounting, HBS Press. 